\title{
Self-medication with over the counter drugs, prevalence of risky practice and its associated factors in pharmacy outlets of Asmara, Eritrea
}

Sirak Tesfamariam ${ }^{1 *}$ (D) Indermeet Singh Anand ${ }^{2}$, Ghide Kaleab ${ }^{1}$, Samson Berhane ${ }^{1}$, Biruck Woldai ${ }^{2}$, Eyasu Habte ${ }^{3}$ and Mulugeta Russom ${ }^{4}$

\begin{abstract}
Background: Although over the counter (OTC) drugs are believed to be relatively safe, their inappropriate use could have serious implications. The aim of the study was to assess the practice of self-medication, prevalence of risky practice and its associated factors in pharmacy outlets of Asmara, Eritrea.

Methods: A descriptive cross-sectional study was conducted among 609 customers in 20 pharmacy outlets in Asmara between August and September, 2017. Two-stage cluster sampling was employed and data were collected using a structured questionnaire through face to face exit interviews. Descriptive statistics and multivariate logistic regression were performed using SPSS (version 22).

Results: Of the 609 customers, $93.7 \%$ had practiced self-medication with OTC drugs; of which $81.8 \%$ were at risky practice. On average, each participant was using OTC drugs at least once a month (Median $=1, \mathrm{IQR}=3.67$ ). Educational level $(p<0.0001)$, religion $(p=0.047)$, occupation $(p=0.027)$ and knowledge regarding OTC drugs $(p=0.019)$ were significantly associated with risky practice. Respondents with elementary and below educational level were fifteen times ( $A O R=15.49, \mathrm{Cl}: 1.97,121.80)$ at higher risk compared to those with higher education, and students were almost three times ( $\mathrm{AOR}=2.96, \mathrm{Cl}: 1.13,7.73$ ) at higher risk than governmental employees. Furthermore, respondents with below average score in knowledge were more likely to be engaged in risky practice ( $A O R=1.83, \mathrm{Cl}: 1.11,3.04)$ compared to those with above average score. The most frequently preferred OTC drug group was analgesics (34.3\%) followed by antipyretics (15.7\%) and cough and cold preparations (14.2\%). About 14\% of the respondents admitted that they had taken more than the recommended dose and $6.9 \%$ had experienced drug related problems following the consumption of OTC drugs. Always, 35\% of the respondents read package insert(s) and $73.9 \%$ check expiry dates while purchasing OTC drugs. Refrigerating OTC drugs, where it is not recommended, was also one of the prominent risky practices.

Conclusions: This study revealed that inappropriate self-medication practice with OTC drugs was prevalent requiring early intervention to minimize the risks.
\end{abstract}

Keywords: Self-medication, Over the counter drugs, Risky practice, Pharmacy outlets, Asmara

\footnotetext{
* Correspondence: sirakino2015@gmail.com

'School of Pharmacy, Asmara College of Health Sciences, Asmara, Eritrea

Full list of author information is available at the end of the article
}

(c) The Author(s). 2019 Open Access This article is distributed under the terms of the Creative Commons Attribution 4.0 International License (http://creativecommons.org/licenses/by/4.0/) which permits unrestricted use, distribution, and reproduction in any medium, provided you give appropriate credit to the original author(s) and the source, provide a link to the Creative Commons license, and indicate if changes were made. The Creative Commons Public Domain Dedication waiver (http://creativecommons.org/publicdomain/zero/1.0/) applies to the data made available in this article, unless otherwise stated. 


\section{Background}

OTC drugs, that can be purchased by consumers without a medical prescription, are believed to be relatively safe and are appropriate for use without the supervision of healthcare professionals [1]. They are classified according to the WHO Anatomical Therapeutic Chemical (ATC) classification in ten categories as follows: analgesics, laxatives, antithrombotic agents, antacids, cough and cold preparations, antihistamines, dermatologicals, throat preparations, nasal preparations and antidiarrheals [2].

At the community level, good self-medication practices can provide benefits such as saving scarce medical resources from being wasted on minor conditions, controlling chronic diseases, and reducing absenteeism from work due to minor ailments $[3,4]$. However, inappropriate self-medication with OTC drugs can have serious implications (including deaths), especially in extremes of ages (pediatrics and geriatrics), pregnant and lactating mothers, and patients with co-morbidities [5-7]. Globally, increasing inappropriate self-medication is seen as a public health concern [5, 8-11].

According to Ranjith et al. as cited by Manohar et al., unregulated or unrestricted availability of OTC drugs is one of the main reasons leading to misuse of these drugs [11]. Moreover, their inappropriate use in developing countries is high due to inadequate knowledge $[12,13]$, lack of exposure to medical information, inadequate infrastructure [10, 14], and weak laws and regulations [14]. Despite the fact that OTC drugs are used inappropriately and causing drug related problems $[8,15]$, their number in the market [16] and incidence of their usage are increasing $[8,13]$.

The list of OTC drugs available in Eritrea (a country in the Horn of Africa), constructed in line with WHO-ATC classification, consists of 55 drugs comprising 68 active ingredients [Unpublished]. These drugs are only available from pharmacy outlets and their presence in shops, groceries, streets and any place other than pharmacy outlet is strictly controlled. Despite the relatively small number of OTC drugs available, common observation of self-medication [12] along with several reported cases is a major concern. For instance, $12.5 \%$ of the adverse drug reactions reported to the Eritrean Pharmacovigilance Center were due to OTC drugs, half of which were related to paracetamol and ibuprofen [15].

The aim of the study was, therefore, to assess the practice of self-medication with OTC drugs, prevalence of risky practice and its associated factors. The results obtained are expected to contribute to decreasing the inappropriate use of OTC drugs through changes in the policies and regulations.

\section{Methods}

\section{Study design and setting}

A descriptive cross-sectional study was conducted in 20 selected pharmacy outlets in Asmara (a capital city of
Eritrea) between 28th August and 21st September, 2017 for a period of 20 days.

\section{Source and study population}

Residents of Asmara were the source population for this study. As per the Administration of Central Region of Eritrea in 2017, Asmara has a population of 427,183. Customers aged 18 years and above, who visited the pharmacy outlets to purchase medicine(s) during the study and willing to participate were considered as a study population. Customers who couldn't communicate in either Tigrigna (Eritrea's national language) or English, who were deaf or mentally unable to communicate were excluded.

\section{Sampling design}

Since the study was done in a community with a large and widely scattered source population, two-stage cluster sampling was used as a sampling design.

First, the list of pharmacy outlets in Asmara was obtained from the National Medicines and Food Administration. Managers of the respective pharmacy outlets were asked to provide estimates of the average number of customers per day. Of the non-systematically arranged 48 pharmacy outlets, 20 sites were randomly selected by probability proportionate to size. The number of subjects to be interviewed at each study site was allocated proportionally to the estimated average number of customers per day. Finally, every 36th customer was interviewed at each study site.

\section{Sample size estimation}

The sample size was calculated by using the single proportion formula without correction for continuity: $\mathbf{n}=\mathbf{Z}^{2 *} \mathbf{P}(\mathbf{1}-\mathbf{P}) / \mathbf{d}^{2}$ [17]. The total sample size (n) was calculated using the following assumptions; proportion (P) was taken as 0.5 for no other similar studies were conducted previously, $\mathrm{Z}$ statistic for $95 \%$ level of confidence $(Z=1.96)$, degree of precision (in proportion of one, $d=0.05)$, and $5 \%$ non-response rate. Then the sample was adjusted by considering design effect (1.5), as two-stage cluster sampling was used as a sampling design, yielding a final sample size of 609 participants.

\section{Data collection tool and approach}

A structured questionnaire (Additional file 1) consisting of four sections was constructed upon a review of similar studies $[8,10,18]$. The questionnaire was designed to capture data on socio-demographic and background characteristics, knowledge, attitude, and practice of self-medication with OTC drugs.

Knowledge was measured using 10 questions designed to assess the general awareness of the respondents about 
OTC drugs and their knowledge regarding indications, contraindications, side effects and usage of those drugs. To find association with risky practice, Knowledge was categorized in to two groups (Knowledge below and above average). The median score, which was found to be 15 points, was used to categorize these groups. The maximum possible cumulative score was 20 , where questions with one possible answer were scored with one point, and each choice of multiple answer question types was scored individually with one point.

Attitude was measured through 11 questions related to safety, efficacy, accessibility, and usage of OTC drugs in Likert scale. A raw score of attitude was used to find further association, where 55 point was the possible maximum score. Increase in raw score indicates increase in positive attitude.

Finally, Practice was assessed through 20 questions that evaluated the subjects' health seeking behavior, and safety of their practice. It also included their responses to the reasons that motivated them to self-medicate, drug related problems encountered, and their preference, frequency, and prevalence of OTC drugs used with respect to the ailments intended to be treated.

After explaining the aims of the study and obtaining written informed consent, face to face exit-interviews were done using a structured questionnaire.

\section{Validity and reliability}

Face and content validity of the questionnaire was determined through a panel discussion of experts in the fields of pharmacy, epidemiology, pharmacoepidemiology, public health, and environmental health.

The interviewers were fifth-year pharmacy students trained to ensure intelligibility of the items so as to maximize the within and between inter-rater consistencies.

\section{Pre-test}

A pre-test was conducted among 30 participants on the 9th and 10th of August, 2017, for checking the comprehensibility of the questions at 6 randomly selected pharmacy outlets which were not included in the main study.

After the pre-test, necessary modifications were made in the final version of the questionnaire.

\section{Statistical analysis}

Data were double entered in CSPro (version 7.0) and analyzed using SPSS (version 22). Descriptive analysis of the socio-demographic variables and practice of self-medication with OTC drugs was done using percentages, and median (IQR). Univariate logistic regression was performed to identify the factors associated with risky practice of OTC drugs. Variables found to be significant at the univariate level were considered for multivariate logistic regression to control the effect of potential confounders. Crude and adjusted odds ratios $(95 \% \mathrm{CI})$ were calculated and all results were deemed to be statistically significant when $p<0.05$.

\section{Operational definitions \\ Knowledge above average}

Score equal to or above the median of knowledge cumulative score.

\section{Knowledge below average}

Score below the median of knowledge cumulative score.

\section{Risky practice}

A respondent was considered to show risky practice if he/ she failed to check expiry dates or read labels, took more than the recommended dose, stored OTC drugs improperly, or continued consuming OTC drugs even though he/ she noticed unusual color, odor or shape changes.

\section{Self-medication}

Use of OTC drugs by the consumer to treat self-recognized disorders or symptoms, or the intermittent or continued use of these drugs prescribed by a physician for chronic or recurring diseases or symptoms.

\section{Results}

Socio-demographic and background characteristics

Out of the 609 participants, 587 completed the interview successfully with a response rate of $96.4 \%$. Three hundred and eighty-one (64.9\%) of the respondents were males and $206(35.1 \%)$ were females, out of which 3 $(1.5 \%)$ were pregnant and $11(5.3 \%)$ were breastfeeding. The median age was 37 years $(\mathrm{IQR}=24)$. Many of the respondents were married (60.1\%), aged between 25 and 34 years (26.7\%), and governmental employees (37.6\%). The educational level was measured in years (attended to formal education) and one-third (33.6\%) of the respondents achieved their higher education. Of the respondents, $72.1 \%$ had no chronic illness; while Asthma or other COPD were reported in $5.2 \%$ of the total cases. The respondents socio-demographic and background information are shown in Tables 1 and 2 below.

Prevalence of self-medication and risky practice with OTC drugs

Almost all respondents (93.7\%) stated that they had practiced self-medication with OTC drugs at least once, which includes $65.1 \%$ males and $34.9 \%$ females. The frequency of self-medication was, on the average, once per month $($ Median $=1, \mathrm{IQR}=3.67)$. Out of those who had practiced self-medication, the majority, $450(81.8 \%)$ demonstrated risky practice. This result is summarized in Fig. 1. 
Table 1 Socio-demographic characteristics of the respondents

\begin{tabular}{|c|c|c|}
\hline Variables & Frequency & Percent \\
\hline \multicolumn{3}{|l|}{ Gender } \\
\hline Male & 381 & 64.9 \\
\hline Female & 206 & 35.1 \\
\hline \multicolumn{3}{|c|}{ Age (Median = 37, IQR =24, Range $=18$ to 95 ) } \\
\hline 18 to 24 & 113 & 19.3 \\
\hline 25 to 34 & 157 & 26.7 \\
\hline 35 to 44 & 118 & 20.1 \\
\hline 45 to 59 & 118 & 20.1 \\
\hline 60 and above & 81 & 13.8 \\
\hline \multicolumn{3}{|l|}{ Marital status } \\
\hline Married & 353 & 60.1 \\
\hline Single & 196 & 33.4 \\
\hline Divorced & 22 & 3.7 \\
\hline Widowed & 16 & 2.7 \\
\hline \multicolumn{3}{|c|}{ Educational level (Median $=12, I Q R=4$, Range $=0$ to 20) } \\
\hline Elementary and below & 44 & 7.5 \\
\hline Junior & 68 & 11.6 \\
\hline Secondary school & 278 & 47.4 \\
\hline Higher Education & 197 & 33.6 \\
\hline \multicolumn{3}{|l|}{ Occupation } \\
\hline Governmental services & 221 & 37.6 \\
\hline Private services & 83 & 14.1 \\
\hline Self-employed & 134 & 22.8 \\
\hline Unemployed & 29 & 4.9 \\
\hline Student & 47 & 8 \\
\hline Housewife & 73 & 12.4 \\
\hline \multicolumn{3}{|l|}{ Religion } \\
\hline Christian & 504 & 85.9 \\
\hline Muslim & 81 & 13.8 \\
\hline Others & 2 & 0.3 \\
\hline
\end{tabular}

Religion: Others contain Jehovah's witness and Atheist

Respondents' practice of self-medication with OTC drugs The majority of respondents reported that they sought information or instruction from pharmacists $(34.8 \%)$ or medical doctors (27.1\%) while self-medicating for the first time. It should be noted that the drugs were not prescribed or suggested by healthcare professionals; rather only information on their use was provided on request. Others (21\%) reported that they got advice from friends and relatives, whilst the remainder (3.4\%) used the internet or mobile applications as a source of information. The common reasons quoted for self-medicating with OTC drugs were ease of accessibility 290 (34\%), saving time 208 (24.4\%), perception of being safe and tolerable 125 (14.7\%), saving money 48 (5.6\%), treating minor ailments 37 (4.3\%) and getting quick relief 31 (3.6\%). Among OTC drug groups, analgesics,
Table 2 Background information of the respondents

\begin{tabular}{lll}
\hline Variables & Frequency & Percent \\
\hline Chronic Illness & 429 & 72.1 \\
No Chronic Disease & 31 & 5.2 \\
Asthma \& Other COPD & 28 & 4.7 \\
Diabetes Mellitus & 27 & 4.5 \\
Hypertension & 14 & 2.4 \\
Orthopedic \& Rheumatologic problems & 14 & 2.4 \\
Kidney Diseases & 13 & 2.2 \\
Cardiac Diseases & 13 & 2.2 \\
Peptic Ulcer or Gl problems & 10 & 1.7 \\
Diabetes Mellitus \& Hypertension & 8 & 1.3 \\
CNS disorders & 8 & 1.3 \\
Others & & \\
Pregnancy & 3 & 1.5 \\
Yes & 203 & 98.5 \\
No & & \\
Breast feeding & 11 & 9.3 \\
Yes & 195 & 94.7 \\
No &
\end{tabular}

Chronic Illness: Others contain Allergies, Benign prostatic hyperplasia, Eye problems, HIV, and Psoriasis. COPD: Chronic obstructive pulmonary diseases, GI: Gastrointestinal, CNS: Central nervous system

antipyretics, and cough and cold preparations were the most frequently used ones (Fig. 2).

Seventy-nine (14.4\%) out of the 550 respondents who had practiced self-medication admitted that they had taken more than the recommended dose at least once. Sixty-five of them took more than the recommended dose to maximize the effectiveness of the medicine, whilst the remaining 14 respondents said that they took more than the recommended dose by mistake.

Of those who had self-medicated, 6.9\% had experienced drug related problems following the consumption of OTC drugs. Ibuprofen was perceived to cause the most drug related problems with gastric upset being the major complaint. Almost half of the respondents (44.7\%) continued taking the drugs even though they had experienced drug related problems, and around 18\% stopped taking the suspected $\operatorname{drug}(\mathrm{s})$. But one-third (31.6\%) informed pharmacists or other healthcare professionals before doing anything.

One-third (35\%) of the respondents said that they always read package insert(s) and $73.9 \%$ said that they always check expiry dates when purchasing OTC drugs (Fig. 3). Around 31\%; however, admitted that they never read anything and $7.5 \%$ never checked expiry dates.

The majority of respondents (64.9\%) reported that they visited health facilities for further diagnosis and treatment if the self-medication failed to work. Other 


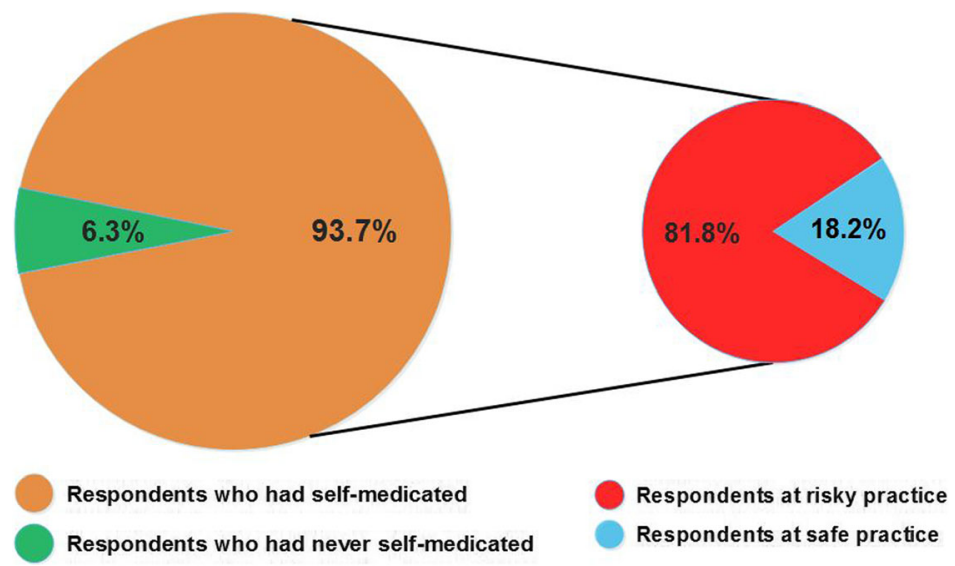

Fig. 1 Prevalence of self-medication and risky practice

reported decisions include: doubling the normal dose (11.5\%), changing to other more powerful OTC drugs (6.9\%), taking some time until the symptoms subside (5.3\%), repeating the same medication $(2.9 \%)$ and using home-remedies or recreational activities (8.6\%). Similarly, the majority of respondents $(70.7 \%)$ claimed that they discarded their OTC drugs if they observed changes in shape, color, or odor. Others either consulted pharmacists (8.9\%) or would continue to take the drug until it reaches its expiry date $(6.2 \%)$.

Three hundred and four $(46.7 \%)$ of the consumers reported that they stored their medicines in dry and cool places where children and direct sunlight could not reach them. Others stored their medicines in a refrigerator (30.9\%), on open tables in bedrooms (18.1\%), kitchens (1.5\%), bathrooms $(1.4 \%)$ or other places.

\section{Factors associated with the risky practice}

The analysis of factors that possibly affect the risky practice are displayed in Table 3. Educational level, occupation, religion, level of knowledge, attitude, and frequency of selfmedication were significantly associated with the risky practice at the univariate level. But, with the adjustment of potential confounders through multivariate logistic regression, educational level $(p<0.0001)$, religion $(p=0.047)$, occupation $(p=0.027)$ and knowledge $(p=0.019)$ were the only variables significantly associated with risky practice. Protective effect of educational level on risky practice was observed and with an increase in the level of education, there was a reduction in the odds of risky practice (Table 3). Respondents who completed junior $(\mathrm{AOR}=4.26, \mathrm{CI}: 1.66,10.88)$ and secondary school $(\mathrm{AOR}=4.10, \mathrm{CI}: 2.35,7.15)$ were four times at higher risk than the reference category, higher

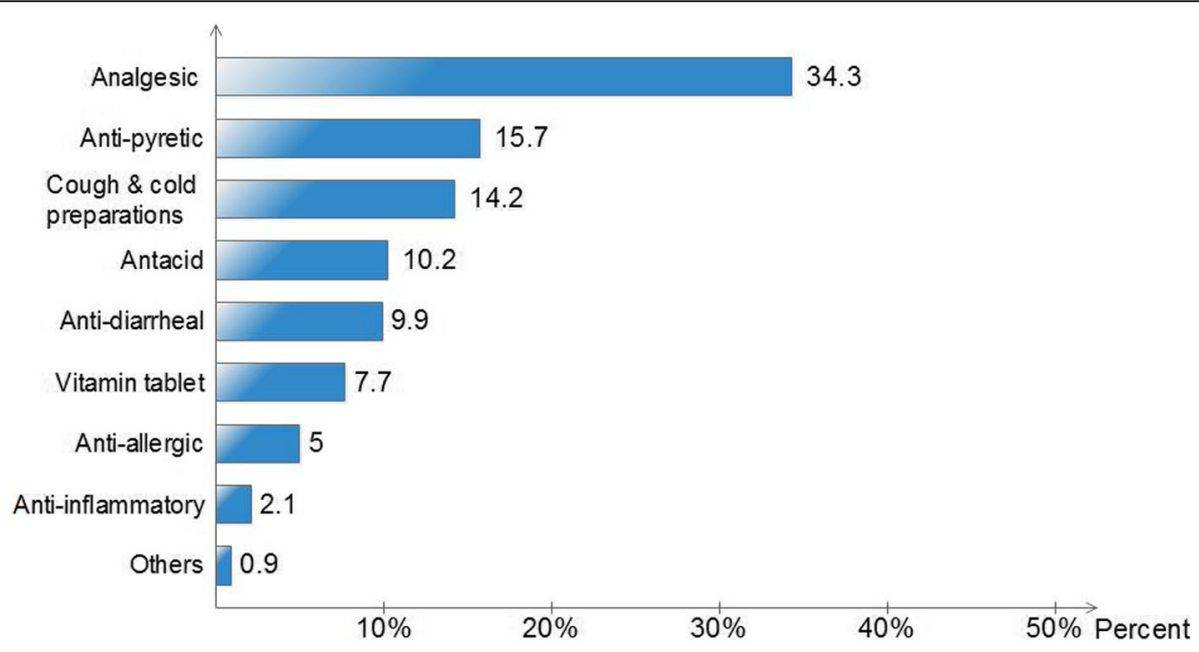

Fig. 2 Most preferred drug classes by respondents for self-medication 


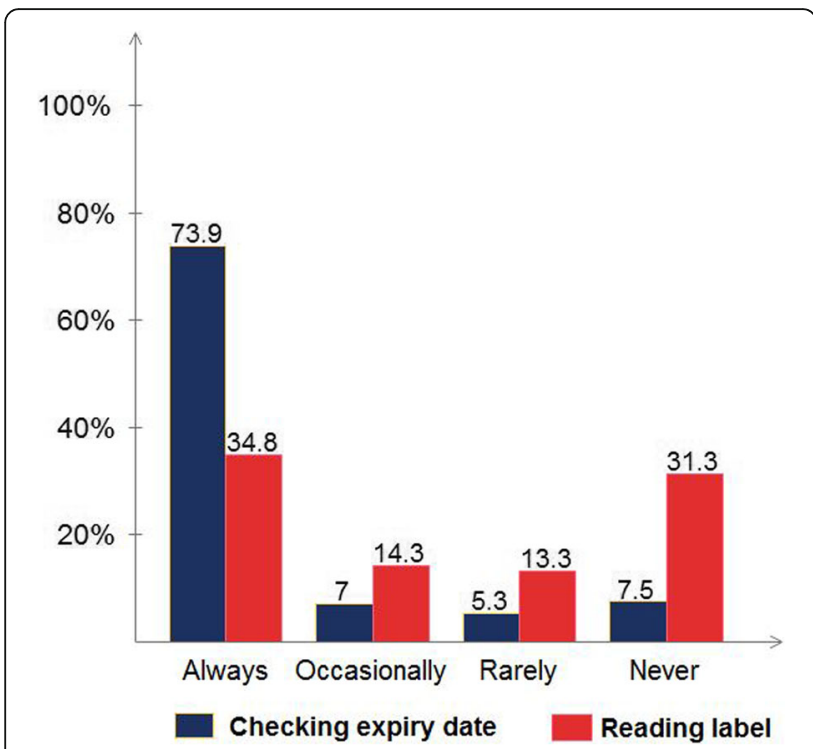

Fig. 3 Habit of checking expiry date and reading labels of the respondents

education. More distantly, respondents with elementary and below educational level were fifteen times $(\mathrm{AOR}=15.49$, CI: $1.97,121.80)$ at higher risk compared to those in higher education. Muslims were two times (AOR $=2.40$, CI: 1.01, 5.72) at higher risk than Christians and students were almost three times at higher risk ( $\mathrm{AOR}=2.96, \mathrm{CI}: 1.13,7.73) \mathrm{com}$ pared to governmental employees. Knowledge regarding OTC drugs was also significantly associated with the risky practice. Respondents with below average score in knowledge were almost two times ( $\mathrm{AOR}=1.83$, CI: $1.11,3.04)$ at higher risk than those having a score above average.

\section{Discussion}

Even though in Asmara, OTC drugs are strictly controlled to be sold in pharmacy outlets only, the self-medication with OTC drugs was found to be prevalently accompanied by high risky practice. The prevalence of self-medication is similar to an Indian study [10] and the prevalence of inappropriate practice is consistent with the findings from a study conducted in Bahrain [19] but much higher than reported by a Nepalese study [8]. Because of difference in the target population among the Indian, Bahraini and the current study, caution should be exercised during result comparison.

In the current study, most of the respondents $(73.9 \%)$ reported that they always check expiry dates before taking OTC drugs. This result emphasizes that the respondents were very cautious about using expired drugs. This result is similar to a previous study conducted in Eritrea [12], but higher than the result of a Nepalese study where only $9.1 \%$ always check expiry dates [8]. On the other hand, the reported habit of reading the package insert before using medicines was very low. Some of the major complaints by the respondents were that package inserts are not available for almost all OTC drugs and the available ones are not prepared in the local language which makes it difficult to comprehend. In addition to the individuals' behavior, the above result might be lowered by the unavailability of package inserts. Other studies showed that in Italy, but conducted among teenagers, $40 \%$ did not read the patient information leaflet last time they took OTC drugs [20]. In descending order, in Nepal 48.2\% [8], Ethiopia 45.5\% [13], India 25\% [11] read leaflets carefully. Moreover, overdosing for the intention of better treatment outcomes and storing medicines in inappropriate places (prominently in a refrigerator) were identified as major risk practices in the customers of pharmacy outlets.

Understanding the sources of information is helpful in designing interventional scheme to promote safe self-medication practice. In our study, despite the most referred source of information being pharmacists, engrossingly, the prevalence of risky practice was high. Observed poor communication bridge between customers and pharmacists could contribute in producing such a controversial result. Comparatively, a higher percentage of pharmacists' involvement in self-medication was observed in studies done in Italy [20], Nepal [21], Ethiopia [13], and Sri Lanka [22]. Easy accessibility of OTC drugs was reported as the main reason that encouraged the respondents to self-medicate. But, in studies done in Palestine [23], India [24], Nepal [25], Egypt [26], respondents self-medicated because they believed that the condition was not serious enough to seek medical attention. Among OTC drug groups, analgesics were the most frequently preferred analogous to studies conducted in Bahrain and India [19, 27].

In the present study, $14.4 \%$ of the respondents admitted that they had taken more than the recommended dose which is much lower than studies conducted in Nepal (86.4\%) [8] and USA (33\%) [28]. Most of the respondents (82\%) took more than the recommended dose to maximize the effectiveness of the medicine which is consistent with that of the USA (91\%) [28]. The majority of respondents, either continued or stopped taking the suspected drug(s) to cause drug related problem before consulting pharmacist or other health care professionals. This implies that there is a lack of knowledge towards reporting side effects to concerned authorities. It is evident that disseminating information to the community on how to report side effects could increase awareness, thereby indirectly decrease complications of drug related problems. The majority of respondents reported that they visited health facilities for further diagnosis and treatment if self-medication failed to work and discarded OTC drugs if they noticed changes in shape, color, or odor. The above-stated results were satisfactory which needs to be empowered. 
Table 3 Univariate analysis and multivariate analysis on the association between respondents' socio-demographic characteristics and risky practice of the respondents

\begin{tabular}{|c|c|c|c|c|}
\hline \multirow[t]{2}{*}{ Variable } & \multicolumn{2}{|c|}{ Univariate analysis } & \multicolumn{2}{|c|}{ Multivariate analysis } \\
\hline & COR & $95 \% \mathrm{Cl}$ & $\mathrm{AOR}$ & $95 \% \mathrm{Cl}$ \\
\hline \multicolumn{5}{|l|}{ Gender } \\
\hline Female & 1.57 & $(0.9,2.53)$ & - & - \\
\hline Male & Ref & & & \\
\hline \multicolumn{5}{|l|}{ Age } \\
\hline 18 to 24 & 1.8 & $(0.85,3.82)$ & - & - \\
\hline 25 to 34 & 1.39 & $(0.70,2.73)$ & - & - \\
\hline 35 to 44 & 1.54 & $(0.75,3.17)$ & - & - \\
\hline 45 to 59 & 1.32 & $(0.65,2.68)$ & - & - \\
\hline 60 and above & Ref & & & \\
\hline \multicolumn{5}{|l|}{ Marital status } \\
\hline Single & 1.44 & $(0.89,2.32)$ & - & - \\
\hline Divorced & 5.62 & $(0.74,42.49)$ & - & - \\
\hline Widowed & 4.01 & $(0.52,30.90)$ & - & - \\
\hline Married & Ref & & & \\
\hline \multicolumn{5}{|l|}{ Educational level } \\
\hline Elementary and below & $21.67^{*}$ & $(2.91,161.24)$ & $15.49^{* *}$ & $(1.97,121.80)$ \\
\hline Junior & $5.15^{* * *}$ & $(2.11,12.58)$ & $4.26^{* *}$ & $(1.66,10.88)$ \\
\hline Secondary school & $4.51^{* * *}$ & $(2.75,7.40)$ & $4.10^{* * *}$ & $(2.35,7.15)$ \\
\hline Higher education & Ref & & Ref & \\
\hline \multicolumn{5}{|l|}{ Occupation } \\
\hline Private service & 1.75 & $(0.89,3.42)$ & 1.18 & $(0.57,2.45)$ \\
\hline Self-employed & $2.1^{*}$ & $(1.15,3.72)$ & 1.05 & $(0.54,2.02)$ \\
\hline Unemployed & 1.9 & $(0.62,5.74)$ & 0.82 & $(0.25,2.72)$ \\
\hline Student & 2.18 & $(0.87,5.45)$ & $2.96^{*}$ & $(1.13,7.73)$ \\
\hline Housewife & $3.56^{* *}$ & $(1.45,8.70)$ & 1.45 & $(0.54,3.88)$ \\
\hline Governmental service & Ref & & Ref & \\
\hline \multicolumn{5}{|l|}{ Chronic Illness } \\
\hline Yes & 0.8 & $(0.5,1.28)$ & - & - \\
\hline No & Ref & & & \\
\hline \multicolumn{5}{|l|}{ Religion } \\
\hline Muslim & $2.42^{*}$ & $(1.08,5.44)$ & $2.40^{*}$ & $(1.01,5.72)$ \\
\hline Christian & Ref & & Ref & \\
\hline \multicolumn{5}{|l|}{ Knowledge of OTC drugs } \\
\hline Below average & $2.36^{* * *}$ & $(1.48,3.78)$ & $1.83^{*}$ & $(1.11,3.04)$ \\
\hline Above average & Ref & & Ref & \\
\hline Attitude towards OTC drugs & $0.9^{* * *}$ & $(0.85,0.95)$ & 0.94 & $(0.88,1.00)$ \\
\hline Frequency of self-medication per month & $1.06^{*}$ & $(1.01,1.11)$ & 1.03 & $(0.98,1.08)$ \\
\hline
\end{tabular}

Note: ${ }^{* *}=p<0.001,{ }^{* *}=p<0.01,{ }^{*}=p<0.05$, Ref $=$ reference category

Educational level, religion, occupation, and knowledge were identified as risk factors for inappropriate use of OTC drugs. As anticipated, a positive effect of educational level and knowledge on risky practice was observed. In a study done in Nepal [8], a similar significant association between educational status and practice of self-medication with OTC drugs was reported. Additionally, there was no significant association between age and practice of self-medication in both studies. Due to unknown reason, the difference in self-medication 
practice between Christians and Muslims was significant with a border case $p$-value $(p=0.047)$. Thus, this can be one avenue for further research to uncover the reasons involved, if there are any. Gender, marital status, and chronic illness categories of the socio-demographic characteristics were found not to affect the risky practice significantly at both univariate and multivariate level of association.

\section{Strengths and limitations}

An adequate sample size considered as fairly representative study participants with a high response rate was the major strengths of the study. It is also assumed that the findings of this study can be generalized to our source of population.

Causality assessment was not run for the reported drug related problems owing to the limitation of the study. Thus, the reported drug related problems might not reflect the actual situation in the field. The questionnaire constructed to measure the knowledge and attitude of the respondents was not psychometrically validated. Besides, as patients were asked to provide history of use and adverse effects, recall bias might affect the data accuracy.

\section{Conclusions}

In summation, inappropriate use of OTC drugs in the Asmara community was found to be of concern requiring further research and stricter control on the use of OTC drugs for self-medication. Refrigerating OTC drugs, where it is not recommended, was one of the prominent risky practices that warrant immediate attention. The reported habit of checking expiry dates before taking OTC drugs was satisfactory, but the habit of reading the package insert was very low. As a remedial action to elevate the habit of reading package inserts, the Ministry of Health of Eritrea should legislate laws concerning the preparation of patient information leaflet in a local language for easy comprehensibility. Low educational level, poor knowledge, religion and occupational status of the respondents (students) were significantly associated with the risky practice of self-medication with OTC drugs. Truth to this nature, health education on medication through different media outlets and in health facilities has paramount importance to promote the safe/appropriate use of OTC drugs.

\section{Additional file}

Additional file 1: Questionnaire for obtaining the knowledge, attitude and practice of self-medication with Over the Counter drugs among pharmacy outlet customers in Asmara, Eritrea. (PDF 327 kb)

\section{Abbreviations}

AOR: Adjusted Odds Ratio; ATC: Anatomical Therapeutic Chemical;

Cl: Confidence Interval; COR: Crude Odds Ratio; CSPro: Census and Survey
Processing System; IQR: Interquartile range; OTC: Over the Counter; SPSS: Statistical Package for Social Sciences; WHO: World Health Organization

\section{Acknowledgements}

We would like to forward our sincere gratitude to Dr. Araia Berhane for his invaluable comments on the manuscript. We owe our thanks to managers of the selected pharmacy outlets in Asmara for allowing us to use their space to interview study participant. We would also like to thank all participants of this study for being cooperative in the process.

Funding

There was no source of funding for the study and manuscript preparation.

\section{Availability of data and materials}

The complete dataset used and/or analyzed during the current study are available from the corresponding author and can be accessed upon a reasonable request.

\section{Authors' contributions}

BW, ISA and MR contributed to the design of the study and the questionnaire, supervised the data collection, and critically reviewed the manuscript for intellectual content. EH contributed to the design of the study and the questionnaire, analyzed the data, interpreted the results, and critically reviewed the manuscript for intellectual content. GK, SB, and ST contributed to the design of the questionnaire, collected, entered and analyzed the data, and wrote the first manuscript. All authors read and approved the final manuscript.

\section{Ethics approval and consent to participate}

Administrative and ethical approval has been granted by the Asmara College of Health Sciences research ethical clearance committee and Ministry of health - health research proposal review and ethical clearance committee. Study participants were informed about the objective of the study and written informed consent was obtained from each respondent. All the information obtained was and will be held confidential and it was and will be used only for this study's purpose.

Consent for publication

Not applicable.

\section{Competing interests}

The authors declare that they have no competing interests.

\section{Publisher's Note}

Springer Nature remains neutral with regard to jurisdictional claims in published maps and institutional affiliations.

\section{Author details}

${ }^{1}$ School of Pharmacy, Asmara College of Health Sciences, Asmara, Eritrea. ${ }^{2}$ Pharmacology and Clinical Pharmacy Unit, School of Pharmacy, Asmara College of Health Sciences, Asmara, Eritrea. ${ }^{3}$ Biostatistics and Epidemiology Unit, School of Public Health, Asmara College of Health Sciences, Asmara, Eritrea. ${ }^{4}$ Eritrean Pharmacovigilance Centre, National Medicine and Food Administration, Ministry of Health, Asmara, Eritrea.

Received: 4 April 2018 Accepted: 23 January 2019

Published online: 06 February 2019

References

1. U.S. Food and Drug Administration: Understanding Over-the-Counter Medicines. https://www.fda.gov/Drugs/ResourcesForYou/Consumers/ BuyingUsingMedicineSafely/UnderstandingOver-the-CounterMedicines/ default.htm. Accessed 29 Mar 2018.

2. Methodology WCCFDS. Guidelines for ATC classification and DDD assignment 2010. Oslo: World Health Organization; 2009.

3. World Health Organization. WHO drug information, vol. 14. Geneva: World Health Organization; 2000. http://apps.who.int/medicinedocs/en/d/Jh1462e/.

4. Vidyavati SDSA, Kamarudin J, Katti SM. Self medication - reasons, risks and benefits. Int J Healthc Biomed Res. 2016;04(04):4.

5. Sherazi BA, Mahmood KT, Amin F, Zaka M, Riaz M, Javed A. Prevalence and measure of self medication: a review. J Pharm Sci Res. 2012;4(3):1774-8. 
6. Ahmad A, Khan MU, Srikanth AB, Kumar B, Singh NK, Trivedi N, Elnour AA Patel I. Evaluation of knowledge, attitude and practice about selfmedication among rural and urban north Indian population. Int J Pharm Clin Res. 2015;7(5):7.

7. Kasabe GH, Tiwari SA, Ghongane BB. A survey of knowledge, attitude and practices of self medication in Pune region. Int J Med Res Health Sci. 2015; 4(4):811-6.

8. Sharma D, Gurung D, Kafle R, Singh S. Knowledge and practice on over-thecounter drugs among adults of age group 20 and above residing in Chapapani-12, Pokhara, Kaski, Nepal. Int I Sci Rep. 2017;3(3):79-86.

9. Jain S. Concept of self medication: a review. Int J Pharm Biol Arch. 2011;2(3): 831-6.

10. Bollu M, Vasanthi B, Chowdary PS, Chaitanya D, Nirojini P, Nadendla RR. Prevalence of self medication among the pharmacy students in Guntur: a questionnaire based study. World J Pharm Pharm Sci. 2014:3:810-26.

11. Manohar HD, Manohar HL. Impact of knowledge and attitude on practices of over the counter medications. IEOM Soc. 2015:775-783.

12. Gebrehiwet T, Elias M, Fesshaye H. Knowledge on commonly used analgesics among pharmacy customers. PharmaFocus. 2009;13(1):6.

13. Eyob T, Weletew A, Retta T, Tarekegn M, Mulisa E. Understanding towards non-prescription medicines among Jimma town drug retail outlets' customers, Ethiopia. Int J Res Med Health Sci. 2015;5(01):2307-083.

14. Kirigia JM, Barry SP. Health challenges in Africa and the way forward. Int Arch Med. 2008;1:1-3.

15. National medicines and food administration of Eritrea Epd: VigiFlow. 2017.

16. Kołłątaj B, Sowa M, Kołłątaj W, Książek P, Szakuła J. The impact of medical knowledge on attitudes towards the use of OTC drugs. Pol J Public Health. 2015;125(3):137-43.

17. Naing L, Winn T, Rusli B. Practical issues in calculating the sample size for prevalence studies. Archi Orofacial Sci. 2006;1:9-14.

18. Jha N, Bajracharya O, Shankar PR. Knowledge, attitude and practice towards medicines among school teachers in Lalitpur district, Nepal before and after an educational intervention. BMC Public Health. 2013;13(1):652.

19. James H, Handu SS, Al Khaja KA, Otoom S, Sequeira RP. Evaluation of the knowledge, attitude and practice of self-medication among first-year medical students. Med Princ Pract. 2006;15(4):270-5.

20. Panero C, Persico L. Attitudes toward and use of over-the-counter medications among teenagers: evidence from an Italian study. Int J Mark Stud. 2016;8(3):11.

21. Mehta RK, Sharma S. Knowledge, attitude and practice of self-medication among medical students. IOSR J Nurs Health Sci. 2015;4(1):89-96.

22. Risfa M, Perera J, Perera P. The usage of over the counter (OTC) medicines and traditional medicines (TMs) for common ailments in selected urban and rural areas in Sri Lanka. Pharm J Sri Lanka. 2015:5:2-8.

23. Sweileh W. Self-medication and over-the-counter practices: a study in Palestine. J Al-Aqsa Unv. 2004:8:1-9.

24. Patel PD, Patel KP, Malhotra SD. Survey of use of over the counter drug and other than over the counter drugs among medical students, nursing and technician staff of a tertiary care teaching hospital. Int J Basic Clin Pharmacol. 2017:6(3):592-6.

25. Shankar P, Partha P, Shenoy N. Self-medication and non-doctor prescription practices in Pokhara valley, Western Nepal: a questionnaire-based study. BMC Fam Pract. 2002;3(17):7.

26. Helal R, Abou-EIWafa H. Self-medication in university students from the city of Mansoura, Egypt. J Env Public Health. 2017;2017:1-6.

27. Mohamed Saleem T, Dilip C, Azeem A. Self-medication with over the counter drugs: a questionnaire based study. Pharm Lett. 2011;3(1):91-8.

28. Interactive $\mathrm{H}$. Attitudes and beliefs about the use of over-the-counter medicines: a dose of reality. National Council on Patient Information and Education; 2002.

Ready to submit your research? Choose BMC and benefit from:

- fast, convenient online submission

- thorough peer review by experienced researchers in your field

- rapid publication on acceptance

- support for research data, including large and complex data types

- gold Open Access which fosters wider collaboration and increased citations

- maximum visibility for your research: over $100 \mathrm{M}$ website views per year

At BMC, research is always in progress.

Learn more biomedcentral.com/submissions 